\title{
Long term treatment of rheumatoid arthritis with sulphasalazine, gold, or penicillamine: a comparison using life-table methods
}

\author{
R D SITUNAYAKE, K A GRINDULis, * AND B McCONKEY
}

From the Dudley Road Hospital, Birmingham, UK

SUMMARY Life-table analysis was applied to the records of 317 patients with rheumatoid arthritis (RA) treated with sulphasalazine (SAS), 201 treated with sodium aurothiomalate (gold), and 163 with penicillamine. They comprised all those treated in our department with these drugs between January 1973 and July 1984. Risks of treatment termination for all reasons were similar for each drug at five years (gold $92 \%$, penicillamine $83 \%$, SAS $81 \%$ ). The risk of treatment termination due to inefficacy was less for gold $(29 \cdot 5 \%)$ than for penicillamine $(38 \cdot 1 \%)$ or sulphasalazine $(41 \cdot 2 \%)$. Adverse effects, however, led to withdrawal of gold in $57 \%$, penicillamine in $41 \cdot 2 \%$, and SAS in $37 \%$; the most effective drugs appeared most toxic. Serious adverse effects were much more common in association with gold (17.4\%) and penicillamine $(12 \cdot 3 \%)$ than with SAS $(1.6 \%)$. Sulphasalazine appears as well tolerated over long periods in RA as gold or pencillamine and is associated with fewer serious adverse effects; of these drugs, it might therefore be considered the agent of first choice.

Many patients with rheumatoid arthritis (RA) need second line drugs but few continue to take them for the long periods necessary to make a significant impact on the disease. ${ }^{1}$ The two drugs most often studied in this respect have been gold and pencillamine. Sulphasalazine (SAS) has also been found to have the properties associated with second line drugs. $^{2-4}$ There have been two studies of long term treatment with SAS, one a comparison with gold, penicillamine and dapsone over two years ${ }^{5}$ and the other a comparison with gold over three and a half years. ${ }^{6}$ Both studies suggested that SAS shares with gold and penicillamine the problems of premature treatment withdrawal, though possibly to a lesser degree and for different reasons.

In this study we examined the incidence, timing, and reasons for treatment termination in patients with RA treated with gold, penicillamine, or SAS for up to five years.

Accepted for publication 18 September 1986.

Correspondence to Dr R D Situnayake, Department of Rheumatology, The Northern General Hospital, Ferry Road, Edinburgh. *Present address: Department of Rheumatology, Leicester Royal Infirmary, Leicester, UK.

\section{Patients and methods}

We reviewed the records of all patients who had received SAS, penicillamine, or gold in the unit for the first time between January 1973 and July 1984. Three hundred and seventeen patients ( 244 women, 73 men) had received SAS, 163 (130 women, 33 men) penicillamine, and 201 (140 women, 61 men) gold. Each patient had definite or classical RA (American Rheumatism Association criteria), and the criteria for initiating treatment with a disease modifying drug were the same throughout. ${ }^{7}$ Clinical details are shown in Table $1 . \chi^{2}$ Analysis with Yates's correction was applied to test for differences in sex, rheumatoid factor positivity, concurrent corticosteroid therapy, and the proportion of patients receiving prior treatment with other disease modifying therapy. Ranked analysis of variance was used to compare age, duration of disease at onset of therapy, initial serum $C$ reactive protein, and erythrocyte sedimentation rate (ESR) since these data were not normally distributed.

Sulphasalazine, enteric coated, was started at a dose of $0.5 \mathrm{~g}$ daily, increasing by $0.5 \mathrm{~g}$ weekly to a maintenance of $2 \mathrm{~g}$ daily in most patients, though higher doses $(2.5-3.0 \mathrm{~g})$ were used in some. Initially, 


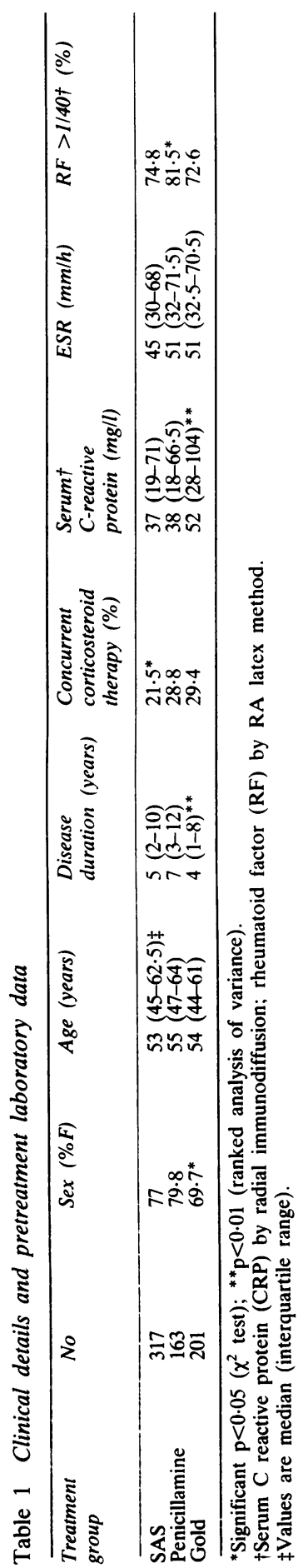

the penicillamine dose was $125 \mathrm{mg}$ daily, increasing by $125 \mathrm{mg}$ increments at two to three month intervals to a maximum of $750 \mathrm{mg}$ daily; maintenance was usually between 375 and $500 \mathrm{mg}$ daily. Sodium aurothiomalate was given at a dose of $50 \mathrm{mg}$ weekly for 20 weeks and then $50 \mathrm{mg}$ on alternate weeks for approximately one year; thereafter $50 \mathrm{mg}$ monthly. All patients were also treated with a non-steroidal anti-inflammatory drug (NSAID) and in some cases (Table 1) with corticosteroids, usually prednisolone $7.5 \mathrm{mg}$ or less daily.

Treatment details were recorded on a card system independent of case notes, thus facilitating information retrieval. For all patients previous disease modifying therapy was noted, and those who were not receiving either gold, penicillamine, or sulphasalazine for the first time were excluded. When treatment was terminated a note was made of the date and reason by the attending doctor. Clinical assessment was at six to 12 week intervals and by 'clinical score'; each patient was given an arbitrary pretreatment score of 100 and at each subsequent visit the score was adjusted by plus or minus 2 or 4 depending on the response to the question 'do you feel better, worse, or the same compared with your last visit?' This method appears to reflect other clinical assessments, including articular index, visual analogue pain scale, and grip strength. ${ }^{8}$

We used the ESR and serum $C$ reactive protein level as laboratory tests of treatment efficacy. Urine was tested for blood and protein before each gold injection, weekly in patients receiving penicillamine and at each clinic visit in those receiving SAS. Treatment was discontinued if proteinuria was $2 \mathrm{~g}$ or more in 24 hours or associated with oedema plus hypoalbuminaemia. Full blood counts, including platelets, were done every six weeks in patients receiving gold or penicillamine and at clinic visits in those receiving SAS. A confirmed platelet count of $100 \times 10^{9} / 1$ or less was regarded as thrombocytopenia.

Standard methods of life-table analysis ${ }^{9}$ were applied to the three groups. Instead of death, treatment termination was taken as the end point. For those patients who died for unrelated reasons while receiving treatment or were lost to follow up the observation time was censored; they were not included in the population at risk from then on. Once generated, the total termination incidence curves were partitioned by the reasons for treatment termination.

Each instance of treatment termination was assigned one main reason: $(a)$ Treatment failure: patients either had no benefit at any time or their disease relapsed during therapy. (b) Adverse effects: major categories were cutaneous reactions, 
Table 2 Number and proportion (\%) of patients receiving therapy with sulphasalazine, gold, or penicillamine as the first to fifth disease modifying drug

\begin{tabular}{|c|c|c|c|c|c|c|}
\hline & $\begin{array}{l}\text { lst drug } \\
n(\%)\end{array}$ & $\begin{array}{l}\text { 2nd drug } \\
n(\%)\end{array}$ & $\begin{array}{l}3 r d \text { drug } \\
n(\%)\end{array}$ & $\begin{array}{l}\text { 4th drug } \\
n(\%)\end{array}$ & $\begin{array}{l}\text { 5th drug } \\
n(\%)\end{array}$ & Total \\
\hline $\begin{array}{l}\text { Sulphasalazine } \\
\text { Gold } \\
\text { Penicillamine* }\end{array}$ & $\begin{array}{r}189 \\
114 \\
48\end{array}\left(\begin{array}{l}59 \cdot 6) \\
56 \cdot 7 \\
29.4\end{array}\right)$ & $\begin{array}{l}85 \\
65 \\
49\end{array}\left(\begin{array}{l}26 \cdot 8) \\
32 \cdot 3) \\
30 \cdot 1)\end{array}\right.$ & $\begin{array}{l}32(10 \cdot 1) \\
19 \\
49(9 \cdot 5) \\
30 \cdot 1)\end{array}$ & $\begin{array}{r}9(2 \cdot 8) \\
1 \\
13(0 \cdot 5)\end{array}$ & $\begin{array}{l}2(0 \cdot 6) \\
2 \\
4 \cdot(1 \cdot 0) \\
2 \cdot 5)\end{array}$ & $\begin{array}{l}317 \\
201 \\
163\end{array}$ \\
\hline
\end{tabular}

*The penicillamine group was significantly different from the two remaining groups $\left(p<0 \cdot 01, \chi^{2}\right.$ test).

loss or alteration of taste, 'central' (nausea, vomiting, dizziness, malaise), gastrointestinal (abdominal pain, diarrhoea), renal (haematuria, proteinuria $>2$ g/day, nephrotic syndrome), and haematological (neutropenia, thrombocytopenia, anaemia, hypogammaglobulinaemia). Other adverse effects were classified as 'miscellaneous'. (c) Improvement: patients were judged to have improved sufficiently to warrant withdrawal of therapy.

\section{Results}

The clinical details of the three groups were similar (Table 1). There was a small but significant difference between the proportion of men treated with gold and penicillamine $(\mathrm{p}<0.05)$, and the penicillamine group contained significantly more seroposi-

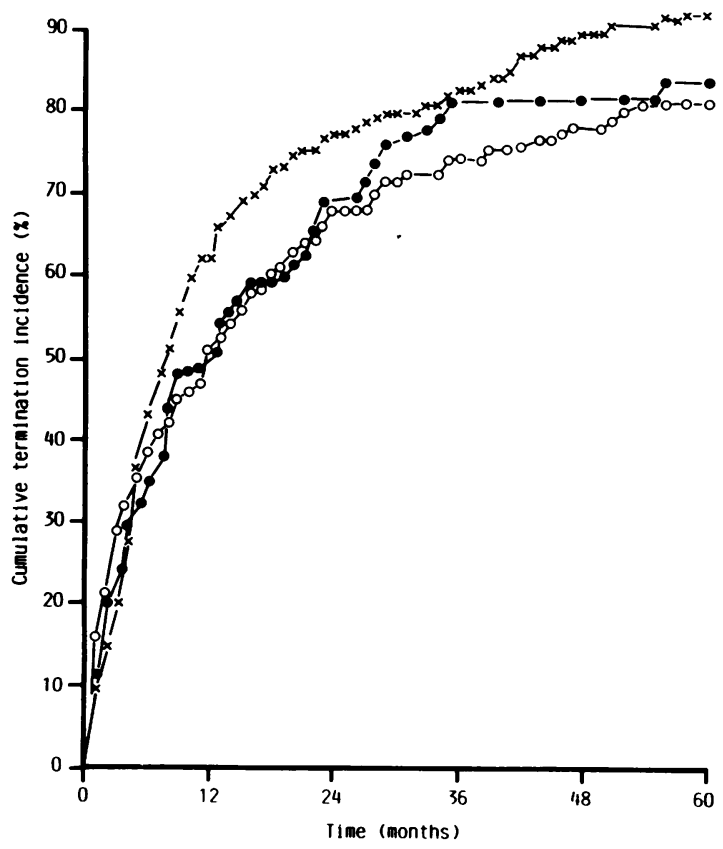

Fig. 1 Total treatment termination for three drugs (gold, penicillamine, and sulphasalazine $)$ over five years $(\times$ gold, - penicillamine, O sulphasalazine).

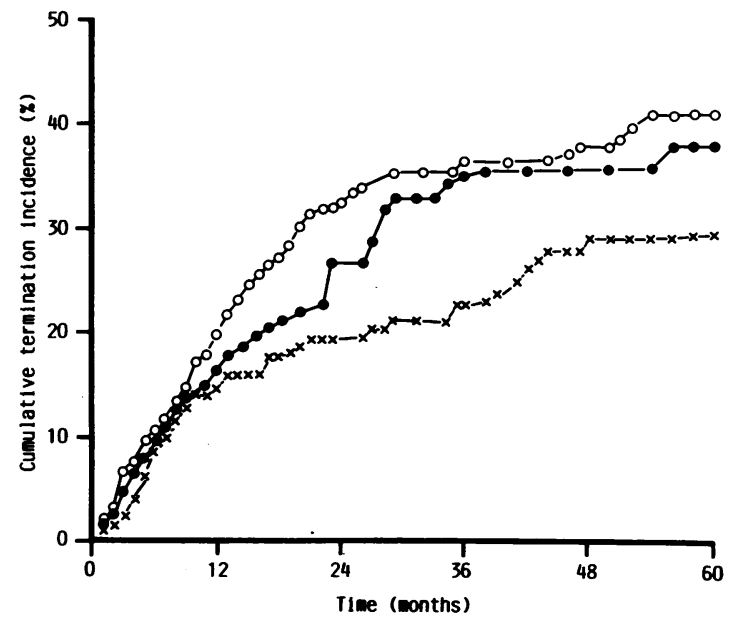

Fig. 2 Treatment termination due to inefficacy (gold, penicillamine, and sulphasalazine $)$ over five years $(\times$ gold, penicillamine, O sulphasalazine).

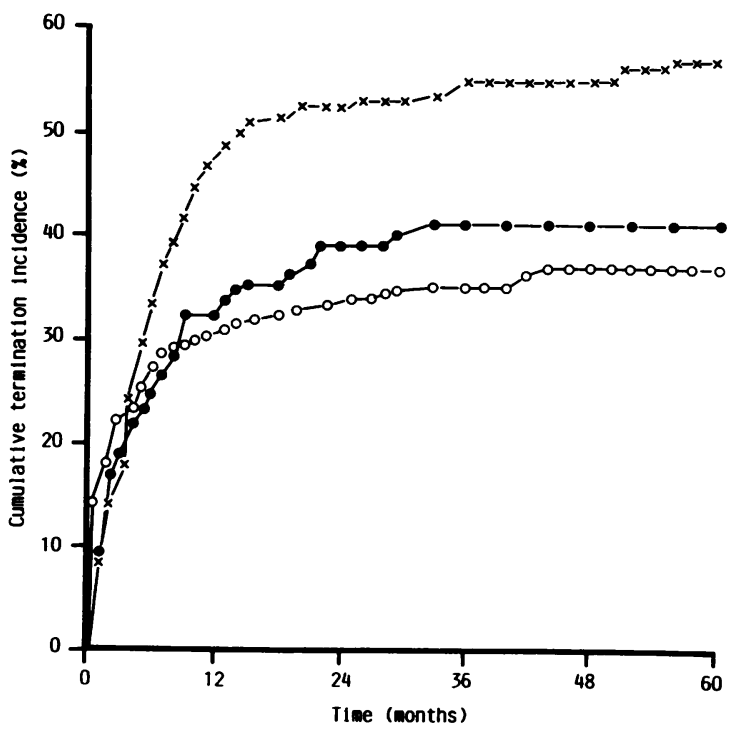

Fig. 3 Treatment termination incidence due to all adverse effects (gold, penicillamine, and sulphasalazine) over five years ( $\times$ gold, 0 penicillamine, $\bigcirc$ sulphasalazine). 
tive patients than those receiving gold $(p<0 \cdot 05)$. Patients treated with gold had had RA for a shorter time than those treated with penicillamine $(p<0.01)$ and sulphasalazine $(\mathrm{p}<0 \cdot 01)$. Fewer patients treated with SAS were receiving concurrent corticosteroid therapy $(p<0.05)$. Ranked analysis of variance showed no significant differences between the three groups for ESR, though serum CRP in the gold group was significantly higher than in the two other groups $(\mathrm{p}<0 \cdot 01)$. The frequency of previous disease modifying therapy with either gold, sulphasalazine, penicillamine, dapsone, levamisole, or chloroquine was assessed for each group (Table 2). With SAS and gold similar proportions of patients had received this therapy as the first to fifth disease modifying drug. Patients treated with penicillamine had more frequently received previous disease modifying therapy before inclusion in the study $(\mathrm{p}<0 \cdot 01)$.

Fig. 1 shows the incidence of treatment termination for all reasons for the three drugs. By six months $39 \%$ patients taking SAS, $36 \%$ penicillamine, and $43 \%$ gold had stopped treatment. At two years the proportions were $68 \%$ with SAS, $69 \%$ penicillamine, and $77 \%$ gold. The curves become flatter thereafter and between two and five years only a further $13 \%$ patients stopped SAS, $14 \%$ penicillamine, and $15 \%$ gold. Thus by five years $81 \%$ patients had stopped SAS, $83 \%$ penicillamine, and $92 \%$ gold. The median time of treatment termination (when $50 \%$ of those who were to stop treatment within five years had done so) was six to seven months for SAS and gold and seven to eight months for penicillamine.

Fig. 2 shows termination incidence curves for treatment failure. By two years $33 \%$ patients had stopped SAS, $27 \%$ penicillamine, and $20 \%$ gold. Between two and five years, withdrawals due to treatment failure increased more slowly and there was no change in the relative order of the drugs.

Small but roughly equal proportions of patients (gold $5 \%$, penicillamine $4 \%$, SAS $3 \%$ ) stopped treatment with each drug within five years because of improvement.

Fig. 3 shows treatment termination due to adverse effects. Relatively few adverse reactions led to withdrawal of treatment later than 24 months; by five years $37 \%$ of patients had stopped SAS, $41 \cdot 2 \%$ penicillamine, and $57 \%$ gold. In patients taking SAS the curve for treatment termination was steepest during the first six months (Fig. 3) largely because of 'central' side effects (nausea, dizziness, headache, and vomiting); the median time for their development was within one month (Fig. 4). Gastrointestinal side effects accounted for a smaller proportion and their median time of occurrence was later,

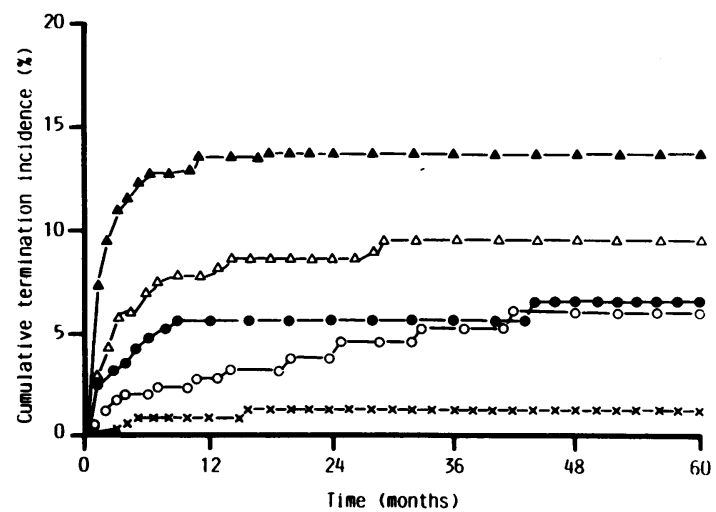

Fig. 4 Treatment termination incidence due to type of adverse effect for sulphasalazine ( $\Delta$ central, $\mathbf{C}$ cutaneous, $\triangle$ gastrointestinal, O miscellaneous, $\times$ haematological).

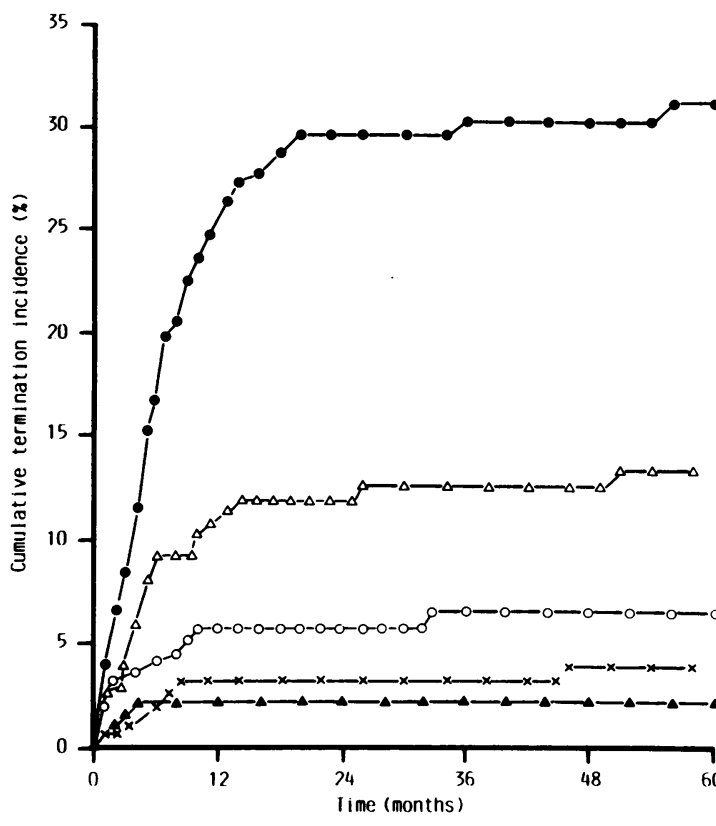

Fig. 5 Treatment termination incidence due to type of adverse effect for gold ( $\Delta$ central, 1 cutaneous. $\triangle$ renal, O miscellaneous, $\times$ haematological).

between two and three months. Haematological adverse effects led to withdrawal of $1.4 \%$ patients. With gold (Fig. 5) the most frequent adverse effects leading to withdrawal were cutaneous reactions and affected $31.2 \%$ patients by five years. Renal side effects of gold (proteinuria or haematuria, or both) led to withdrawal in $13.5 \%$ patients and haematological side effects in $3.9 \%$. With penicillamine (Fig. 6) renal adverse effects led to withdrawal of $10.5 \%$ 


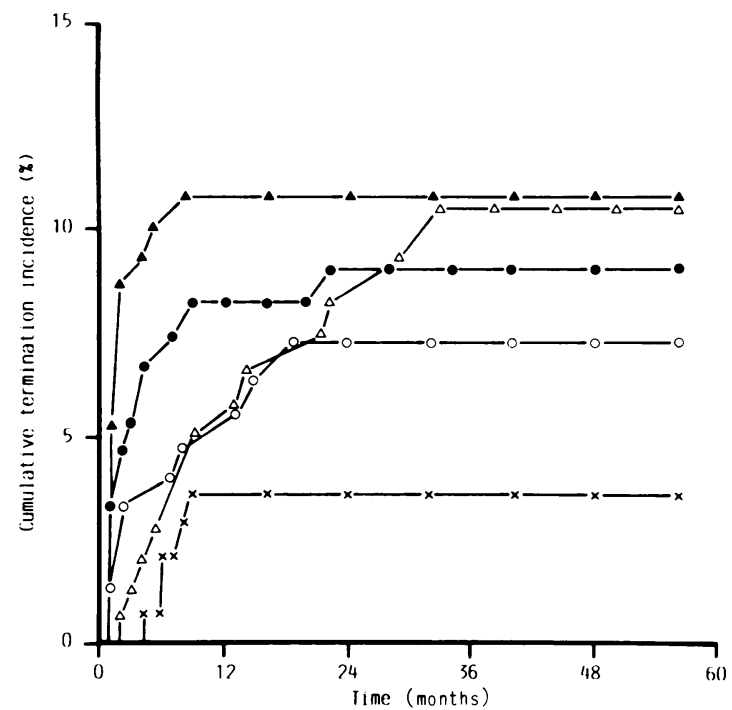

Fig. 6 Treatment termination incidence due to type of adverse effect for penicillamine ( $\mathbf{\Delta}$ taste loss.

cutaneous, $\triangle$ renal. $\bigcirc$ miscellaneous. $\times$ haematological).

patients, taste loss $10 \cdot 8 \%$, and cutaneous reactions $9 \%$. Haematological adverse effects caused $3 \cdot 6 \%$ to stop penicillamine.

To categorise an adverse effect as 'serious' is arbitrary, but we considered that haematological, renal, pulmonary, and generalised cutaneous reactions represented unreasonable additional risks to the patient and they are summarised in Table 3 . With SAS five serious adverse reactions (four haematological, one cutaneous) were encountered during treatment of 317 patients. One patient developed neutropenia (total white cell count $2 \cdot 4 \times 10^{9} / 1$ with less than $11 \%$ polymorphs), but recovery occurred within eight days of stopping treatment. Three patients had severe anaemia. In two it was megaloblastic and haemoglobin fell to $7 \cdot 7$ $\mathrm{g} / \mathrm{dl}(77 \mathrm{~g} / \mathrm{l})$ and $6.9 \mathrm{~g} / \mathrm{dl}(69 \mathrm{~g} / \mathrm{l})$ respectively. In the first patient serum folate was $<1.0 \mu \mathrm{g} / \mathrm{l}$ (normal range 3-20) and vitamin $B_{12}$ normal; in the second serum vitamin $B_{12}$ was $87 \mathrm{ng} / \mathrm{l}$ (normal range 150-1000) and folate normal. Investigations did not provide evidence of malabsorption or pernicious anaemia, and the anaemia was attributed to SAS in each case. The third case of anaemia $(\mathrm{Hb} \mathrm{5.3} \mathrm{g} / \mathrm{dl}$ $(53 \mathrm{~g} / \mathrm{l})$ ) was normocytic, hypochromic with normal serum iron, vitamin $B_{12}$, and folate and responded to transfusion; this may have been a sideroblastic anaemia. One severe generalised skin eruption occurred with SAS.

More adverse reactions were classified as serious with gold and penicillamine than with SAS (Table 3). Predominant were proteinuria and haematuria, and four patients receiving gold and three receiving penicillamine developed a nephrotic syndrome. Five cases of thrombocytopenia were encountered during gold treatment and five during penicillamine therapy. One patient receiving gold developed hypogammaglobulinaemia, four had exfoliative dermatitis, one interstitial pneumonitis, and one an anaphylactic reaction to injection of the first dose.

\section{Discussion}

Several factors influenced our choice of particular disease modifying therapy. During the early part of the study gold was usually our drug of first choice. Later, we more often chose SAS since we had evidence that this drug had a more favourable safety profile. These factors explain in part the finding that patients treated with penicillamine had more frequently received previous therapy with other disease modifying drugs, and it is possible that this might have had an unfavourable effect on treatment outcome. A substantial number of patients in each group, however, had already had some other disease modifying drug (Table 2). The differences between groups with respect to sex, disease duration, and seropositivity seem to us unlikely to have influenced drug tolerance. Although more patients treated with gold and penicillamine were receiving therapy with corticosteroids than those treated with sulphasala-

Table 3 Serious adverse effects during sulphasalazine, penicillamine, and gold therapy

\begin{tabular}{|c|c|c|c|c|c|}
\hline Drug & Haematological & Cutaneous & Renal & Miscellaneous & Total \\
\hline $\begin{array}{l}\text { Sulphasalazine } \\
\qquad(\mathrm{n}=317)\end{array}$ & $\begin{array}{l}\text { Severe anaemia (3) } \\
\text { Neutropenia (1) }\end{array}$ & $\begin{array}{l}\text { Generalised } \\
\text { cutaneous cruption (1) }\end{array}$ & - & - & 5 \\
\hline $\begin{array}{l}\text { Penicillamine } \\
(n=163)\end{array}$ & Thrombocytopenia (5) & - & $\begin{array}{l}\text { Proteinuria }+ \\
\text { haematuria (12) } \\
\text { Nephrotic syndrome (3) }\end{array}$ & - & 20 \\
\hline Gold $(n=201)$ & $\begin{array}{l}\text { Thrombocytopenia (5) } \\
\text { Hypogamma- } \\
\text { globulinaemia (1) }\end{array}$ & $\begin{array}{l}\text { Exfoliative } \\
\text { dermatitis (4) }\end{array}$ & $\begin{array}{l}\text { Proteinuria }+ \\
\text { haematuria (19) } \\
\text { Nephrotic syndrome (4) }\end{array}$ & $\begin{array}{l}\text { Interstitial } \\
\text { pneumonitis (1) } \\
\text { Anaphylaxis (1) }\end{array}$ & 35 \\
\hline
\end{tabular}


zine, steroid doses were small and were not changed. The effect of low dose corticosteroids on treatment outcome is unknown, though in one study steroids did not influence the rate of gold withdrawal. ${ }^{10}$

Comparisons of drugs also depend on uniform methods of assessing their efficacy. We used one subjective and two objective criteria: the 'clinical score', ESR, and serum $C$ reactive protein. These three assessments together compare favourably with other 'process' measurements of rheumatoid activity. $^{8}$

Life-table analysis as a method of displaying data has been explored by Richter $e t a l,{ }^{11}$ and we felt it to be the most appropriate means of depicting the reasons for treatment termination with each drug since it displays graphically both the time and cumulative importance of each. It also enabled us to include greater numbers in the analyses since we were not restricted to the inclusion of patients who could have completed a certain length of treatment, a device necessary in an 'intention to treat' analysis.

Treatment termination rates with each drug were similar and comparable with those of most other studies, ${ }^{1}$ which report approximately $50 \%$ treatment withdrawal by 12 months due mainly to adverse reactions. In the only previous analysis of gold using life-table methods Richter $e$ al found that $50 \%$ of 93 patients had stopped treatment by 5 years. ${ }^{11}$ This result is much better than that achieved in other studies and our own ( $92 \%$ withdrawal at five years), but Richter et al included only patients who had already received $1 \mathrm{~g}$ of gold ( 20 weeks' treatment) at the time of entry.

The three drugs were infrequently stopped because they were effective and miscellaneous reasons accounted for no more than $6-7 \%$ of terminations with each by five years. There were thus two main reasons for withdrawal: treatment was ineffective or intolerable adverse effects occurred. Over five years $29.5 \%$ of patients discontinued gold owing to inefficacy of the drug compared with $38 \%$ of those receiving penicillamine and $41 \%$ receiving SAS. Thus gold appears superior to the other drugs. The data on adverse effects, however, place them in the converse order; unwanted reactions were more common with gold than with SAS or penicillamine (gold $57 \%$; penicillamine $41 \%$; SAS $37 \%$ ). Severe adverse effects were far more common with gold and penicillamine than with SAS; only patients receiving gold or penicillamine developed proteinuria or thrombocytopenia, though thrombocytopenia is known to be an occasional hazard of SAS therapy; exfoliative dermatitis also occurred only during treatment with gold, though a severe generalised skin eruption was encountered in one patient receiving SAS. Haematological adverse effects did. occur with SAS; there was one case of neutropeni and three of severe anaemia. In one patient the anaemia may have been due to folate deficiency产 SAS is known to stress folate metabolism. ${ }^{12}{ }^{13}$ In prospective study, however, SAS did not appear t $\overrightarrow{8}$ cause folate deficiency in rheumatoid patients. $\stackrel{10}{\infty}$ The causes of anaemia in the other two patients are uncertain and their relation to SAS in doubt.

For both gold and penicillamine the frequency and type of adverse reactions are in accord wit general experience. ${ }^{10} 15-21$ Our finding of $10 \cdot 8 \%$ termination of penicillamine for dysgeusia is highe? than found in most previous reports, though the incidence of this complication is up to $33 \%{ }^{21}$ Ou ${ }^{2}$ patients were told that taste alteration or loss wass likely to be temporary but many would not tolerate the symptom.

No previous studies have considered the treat $\vec{z}$ ment of RA with SAS for periods up to five years. I the only other long term study $49 \%$ patients stoppe® taking SAS by two years ${ }^{6}$; our figure for the same period was $68 \%$. We cannot satisfactorily explaing the difference, but in both studies withdrawal was due mainly to nausea, dizziness, and dyspepsia. It is uncertain whether these are central effects of sulphapyridine or local gastric intolerance, or botho Gastrointestinal side effects of SAS appear to b\& more common in RA than in inflammatory bowes disease $^{22}$ perhaps because of the additive effects of NSAIDs in RA and because of difficulty in distin guishing some drug and disease effects in inflamma? tory bowel disease.

We have investigated whether our performanco with these three drugs has improved by compariso with our previously published figures relating to 1973-78. For penicillamine our policy has changegु little since 1978 and the present figures have alteree little (48\% termination after one year and $69 \%$ after two years). Figures for gold have improved slightl over the same period from $76 \%$ to $64 \%$ at one yeap and from $86 \%$ to $78 \%$ at two years, reflecting oux. improved experience with the drug. For sulphasalad zine we have treated 196 patients since the 1978 analysis; the one year figures have improved from $53 \%$ to $49.4 \%$ and those at two years from $73 \%$ to $65.8 \%$. The lack of major improvement in drus tolerance may be explained by the fact that we rapidly learnt that gradual increments in dose were necessary for optimum compliance.

Could these results be improved? Before com parisons with other studies are made it must bo realised that treatment termination rates are often better under formal trial protocols ${ }^{20}$ because thers appears to be a higher threshold for treatmey withdrawal than in routine clinical practice. Im 
provements with gold might be made with flexible dose schemes ${ }^{23}$ and by adopting low dose regimens to reintroduce therapy after cutaneous reactions. ${ }^{24}$ Penicillamine is less toxic at low doses ${ }^{19}$ but may also be less potent. With SAS a dose higher than our usual $2 \mathrm{~g}$ daily might be better but probably at the cost of increased side effects. ${ }^{25}$ Lower doses remain to be tested and might, if effective, be associated with less adverse effects. It has been suggested that antiemetics might help nausea during SAS therapy, ${ }^{25}$ but our experience has not been encouraging. The assessment of acetylator phenotype may help to reduce toxicity by permitting lower doses in slow acetylators, and desensitisation after SAS induced rashes is simple and effective. ${ }^{26}$ It is, however, unlikely that any of these measures will allow major improvements in the performance of these drugs.

The data show that there is little difference between SAS, gold, and penicillamine when judged either by the frequency of treatment termination due to adverse effects or by inefficacy within five years. Since sulphasalazine was least often associated with serious adverse effects it is now our first choice when initiating disease modifying therapy for RA.

\section{References}

1 Paulus H E. An overview of benefit/risk of disease modifying treatment of RA as of today. Ann Rheum Dis 1982; 41 (suppl): 26-60.

2 McConkey B, Amos R S, Durham S, Forster P J G. Hubball S, Walsh L. Sulphasalazine in rheumatoid arthritis. Br Med J 1980; 280: 442-4.

3 Bird H A. Dixon I S. Pickup M E. A biochemical assessment of sulphasalazine in rheumatoid arthritis. $J$ Rheumatol 1982; 9: 36-45.

4 Pullar T, Hunter J A. Capell H A. Sulphasalazine in rheumatoid arthritis: a double blind comparison of sulphasalazine with placebo and sodium aurothiomalate. $\mathrm{Br}$ Med J 1983; 287: $1102-4$.

5 Grindulis K A. McConkey B. Outcome of attempts to treat rheumatoid arthritis with gold, penicillamine, sulphasalazine, or dapsone. Ann Rheum Dis 1984; 43: 398-401.

6 Bax D E, Amos R S. Sulphasalazine: a safe, effective agent for prolonged control of RA. A comparison with sodium aurothiomalate. Ann Rheum Dis 1985; 44: 194-8.

7 Constable T J, Crockson A P, Crockson R A. McConkey B.
Drug treatment of rheumatoid arthritis: a systematic approach. Lancet 1975; i: 1176-80.

8 Grindulis K A. Calverley M. Constable T J, Forster P J G. Khalafalla Ahmed M E. McConkey B. A comparison between clinical and laboratory tests in rheumatoid arthritis. Scand $J$ Rheumatol 1983; 12: 285-8.

9 Armitage P. In: Statistical methods and medical research. Oxford: Blackwell Scientific. 1983: 408-14.

10 Sambrook P N. Browne C D. Champion G D. Day R O. Vallance J B, Warwick N. Termination of treatment with gold sodium thiomalate in RA. J Rheumatol 1982: 9: 932-4.

11 Richter J A. Runge L A. Pinals R S. Oates R P. Analysis of treatment terminations with gold and antimalarial compounds in RA. J Rheumatol 1980; 7: 153-9.

12 Franklin J L, Rosenberg I H. Impaired folic acid absorption in inflammatory bowel disease: effects of salicylazosulphapyridine. Gastroenterology 1973: 64: 517-25.

13 Selhub J, Dhar J, Rosenberg I H. Inhibition of folate enzymes by sulphasalazine. J Clin Invest 1978: 61: 221-4.

14 Grindulis K A. McConkey B. Does sulphasalazine cause folate deficiency in rheumatoid arthritis? Scand J Rheumatol 1985; 14: 265-70.

15 Rothermilch N O. Chrysotherapy in rheumatoid arthritis. Clin Rheum Dis 1979; 5: 631-40.

16 Srinivasan R, Miller B L. Paulus H E. Long-term chrysotherapy in rheumatoid arthritis. Arthritis Rheum 1979; 22: 105-10.

17 Kean M F, Anastassiades T P. Long-term chrysotherapy. Arthritis Rheum 1979; 22: 495-507.

18 Webley M, Coomes E N. An assessment of penicillamine therapy in rheumatoid arthritis and the influence of gold therapy. $J$ Rheumatol 1979; 66: 20-4.

19 Kean M F. Dwosh I L. Anastassiades T P. Ford P M. Kelly M G. The toxicity pattern of D-penicillamine therapy. A guide to its use in rheumatoid arthritis. Arthritis Rheum 1980; 23: $158-64$.

20 Thompson P W. Kirwan J R. Barnes C G. Practical results of treatment with disease modifying anti-rheumatoid drugs. $\mathrm{Br} \mathrm{J}$ Rheumatol 1985; 24: 167-75.

21 Multicentre trial group. Controlled trial of D-penicillamine in severe rheumatoid arthritis. Lancet 1973; i: 275-80.

22 Nielsen $\mathrm{O} \mathbf{H}$. Sulphasalazine intolerance. A retrospective survey of the reasons for discontinuing treatment with sulphasalazine in patients with inflammatory bowel disease. Scand $J$ Gastroenterol 1982: 17: 389-93.

23 Gumpel J M. Cyclophosphamide, gold and penicillaminedisease-modifying drugs in rheumatoid arthritis. Tailored dosage and ultimate success. Rheumatol Rehabil 1976; 15: 217-20.

24 Klinefelter H F. Reinstitution of gold therapy in rheumatoid arthritis after mucocutaneous reactions. J Rheumatol 1985; 2: 21-7.

25 Pullar T, Hunter J A. Capell H A. Sulphasalazine in the treatment of rheumatoid arthritis: relationship of dose and serum levels to efficacy. Br $J$ Rheumatol 1985; 24: 269-76.

26 Holdsworth C D. Sulphasalazine desensitisation. Br Med J 1981; 282: 110-11. 